\title{
Impact of Visceral Fat Area in Colorectal Surgery
}

\author{
Ji Yeon Kim \\ Department of Surgery, Chungnam National University Hospital, Daejeon, Korea
}

\section{See Article on Page 20-26}

Many studies have demonstrated a close relationship between body fat distribution and the occurrence of metabolic syndrome; an excess of abdominal adipose tissue, especially intra-abdominal visceral fat, leads to obesity-related complications [1]. Visceral obesity is closely related to the development of colorectal cancer, as well as other metabolic complications [2], and the distribution of adipose tissue also seems to be important in the pathogenesis of colorectal cancer [3]. Therefore, analytical morphometric assessment has recently been proposed to improve preoperative risk stratification, and the body mass index (BMI) has been widely used to express the degree of obesity, although it does not always adequately reflect the degree of visceral fat [4]. Accordingly, several other body composition parameters, such as the visceral fat area (VFA), have been assessed by using preoperative staging computed tomography in patients undergoing various surgical procedures [5].

Some cutoff values of the VFA in the Korean population have been reported for use as a diagnostic criterion of abdominal obesity, and the value of the VFA associated with an increased risk of obesity-related disorder in Korea was reported to be $103.8 \mathrm{~cm}^{2}$ [6]. Also, Oka et al. [7] more recently reported cutoff levels of the VFA in the Japanese population, with VFA $>130 \mathrm{~cm}^{2}$ in men and VFA $>90 \mathrm{~cm}^{2}$ in women indicating obesity.

Many reports state that obese patients have unfavorable surgical outcomes, including longer operative time, increased postoperative complication rate, increased conversion rate, prolonged hospital stay [8] and shorter disease-free survival [9] after resection for colorectal cancer. A meta-analysis revealed high BMI to be as-

Correspondence to: Ji Yeon Kim, M.D.

Division of Colorectal Surgery, Department of Surgery, Chungnam National University School of Medicine, 33 Munhwa-ro, Jung-gu, Daejeon 35015, Korea

Tel: +82-42-280-7175, Fax: +82-42-257-8024

E-mail:jkim@cnu.ac.kr

(C) 2016 The Korean Society of Coloproctology

This is an open-access article distributed under the terms of the Creative Commons Attribution NonCommercial License (http://creativecommons.org/licenses/by-nc/4.0) which permits unrestricted noncommercial use, distribution, and reproduction in any medium, provided the original work is properly cited. sociated with higher risks of infectious complications, including surgical site infections and pulmonary infection [10]. Recently, however, Yu et al. [11] investigated the distribution of the VFA and general obesity in the Korean population, and they concluded that visceral obesity had no influence on intraoperative difficulties, postoperative complications, and postoperative recovery in patients with sigmoid colon or rectal cancer. They did not clearly state the reason obesity did not influence the operative outcomes in their research, although they presumed the cutoff value of the VFA would affect their results.

The associations between obesity and gastrointestinal disease are of variable strength, and the underlying mechanisms are incompletely understood, but obesity and metabolic syndrome clearly have a significant, potentially avoidable, and often underrecognized, impact on the population burden of gastrointestinal disease [12]. No doubt, visceral obesity plays a strong role in the development of metabolic syndrome; however, some controversy still remain and needs to be resolved between the relationship of visceral obesity and postoperative complications. To clarify the correlation between visceral obesity and operative outcome, we need further investigation to identify more accurate predictors, such as BMI, body surface area and VFA/subcutaneous fat area ratio, for the outcomes of colorectal surgery.

\section{CONFLICT OF INTEREST}

No potential conflict of interest relevant to this article was reported.

\section{REFERENCES}

1. Kobayashi H, Nakamura T, Miyaoka K, Nishida M, Funahashi T, Yamashita S, et al. Visceral fat accumulation contributes to insulin resistance, small-sized low-density lipoprotein, and progression of coronary artery disease in middle-aged non-obese Japanese men. Jpn Circ J 2001;65:193-9.

2. Lohsiriwat V, Pongsanguansuk W, Lertakyamanee N, Lohsiriwat D. Impact of metabolic syndrome on the short-term outcomes of colorectal cancer surgery. Dis Colon Rectum 2010;53:186-91.

3. Wang Y, Jacobs EJ, Patel AV, Rodriguez C, McCullough ML, Thun MJ, et al. A prospective study of waist circumference and body 
mass index in relation to colorectal cancer incidence. Cancer Causes Control 2008;19:783-92.

4. Tsujinaka S, Konishi F, Kawamura YJ, Saito M, Tajima N, Tanaka O, et al. Visceral obesity predicts surgical outcomes after laparoscopic colectomy for sigmoid colon cancer. Dis Colon Rectum 2008;51: 1757-65.

5. Pecorelli N, Carrara G, De Cobelli F, Cristel G, Damascelli A, Balzano G, et al. Effect of sarcopenia and visceral obesity on mortality and pancreatic fistula following pancreatic cancer surgery. Br J Surg 2016 Jan 18 [Epub]. http://dx.doi.org/10.1002/bjs.10063.

6. Kim JA, Choi CJ, Yum KS. Cut-off values of visceral fat area and waist circumference: diagnostic criteria for abdominal obesity in a Korean population. J Korean Med Sci 2006;21:1048-53.

7. Oka R, Kobayashi J, Yagi K, Tanii H, Miyamoto S, Asano A, et al. Reassessment of the cutoff values of waist circumference and visceral fat area for identifying Japanese subjects at risk for the metabolic syndrome. Diabetes Res Clin Pract 2008;79:474-81.
8. Pikarsky AJ, Saida Y, Yamaguchi T, Martinez S, Chen W, Weiss $\mathrm{EG}$, et al. Is obesity a high-risk factor for laparoscopic colorectal surgery? Surg Endosc 2002;16:855-8.

9. Moon HG, Ju YT, Jeong CY, Jung EJ, Lee YJ, Hong SC, et al. Visceral obesity may affect oncologic outcome in patients with colorectal cancer. Ann Surg Oncol 2008;15:1918-22.

10. Liu Y, Dong Y, Wu X, Chen H, Wang S. Influence of high body mass index on mortality and infectious outcomes in patients who underwent open gastrointestinal surgery: a meta-analysis. Am J Infect Control 2016 Jan 29 [Epub]. http://dx.doi.org/10.1016/j.ajic.2015.12.009.

11. Yu H, Joh YG, Son GM, Kim HS, Jo HJ, Kim HY. Distribution and impact of the visceral fat area in patients with colorectal cancer. Ann Coloproctol 2016;32:20-6.

12. Feakins RM. Obesity and metabolic syndrome: pathological effects on the gastrointestinal tract. Histopathology. 2015 Nov 24 [Epub]. http://dx.doi.org/10.1111/his.12907. 